\title{
1. Introduction: Indigenous and Minority Placenames - Australian and International Perspectives
}

\author{
Ian D. Clark \\ Federation University Australia \\ Luise Hercus \\ The Australian National University \\ Laura Kostanski \\ Federation University Australia
}

This book is the third volume in a series dedicated to Australian placenames. The earlier volumes are Koch and Hercus (eds) 2009, Aboriginal Placenames: Naming and Re-Naming the Australian Landscape (The Australian National University E Press and Aboriginal History), and Hercus, Hodges and Simpson (eds) 2002, The Land is a Map: Placenames of Indigenous Origin in Australia (Pandanus Books and Pacific Linguistics, Canberra). As in the earlier volumes, many of the papers in this volume originated as papers at a placenames conference, in this case one hosted by the University of Ballarat in 2007 that featured Australian and international speakers who spoke on aspects of Indigenous and minority toponyms. Added to these papers are three papers that are recipients of the Murray Chapman Award: Nash (Chapter 2) and Wafer (Chapter 4) won the award in 2011, and Nash (Chapter 3) in 2012. This award is sponsored by the Geographical Names Board of NSW. The papers have been arranged geographically, starting with New South Wales and ending with four international papers presented at the Ballarat conference.

The first collection of papers concerns New South Wales. The first paper by David Nash relates to comitative placenames in central NSW where he notes there is a concentration of placenames ending in -dra,-drie, -dgery and similar English spellings in central NSW. Historical investigation of these names reveals a subset with justifiable Wiradjuri etymologies, all involving the nominal Comitative ('with, having') suffix -DHurray. Similar placenames with less well known origins are also considered. The study reveals some patterns in the form of these placenames, including a previously unreported dependence of the form of the suffix on the final sound of the root word. The geographic distribution of the placenames is shown to match the extent of Wiradjuri country. 
David Nash's second paper is on the diminutive suffix-dool in placenames of central north NSW where he has found there is a concentration of placenames ending in -dool (and-dule) in central northern NSW and adjacent Queensland, of which Angledool is probably the most widely known today. The study of over a dozen of these names shows they include the Gamilaraay and Yuwaalaraay nominal suffix - DHuul, with a definite or individuating meaning. The methodology of the study is to move from better known origins to inferred origins (and some speculation). General observations are made on the semantics of the stems, and of diminutives as toponyms. Another cluster of -dool placenames in the NSW Riverina is briefly discussed: there the syllable appears to be of disparate origins, and some-dool placenames are proposed to be a transplant (copied from central northern NSW).

Jim Wafer's paper is concerned with placenames as a guide to language distribution in the Upper Hunter, and the landnám problem in Australian toponomastics. The question of what language or languages were spoken in the Upper Hunter region of NSW is vexed. The NSW Aboriginal Languages Research and Resource Centre's current draft 'Map of NSW Aboriginal languages' leaves the Upper Hunter blank. In earlier attempts to identify the languages spoken in this region, from the coastal areas occupied by 'Awabakal' and 'Worimi' to the headwaters of the Hunter in the Great Dividing Range, Tindale filled the space with a language he called 'Geawegal', and the Central Mapping Authority ('CMA') of NSW and Horton followed suit. Brayshaw, on the other hand, analyses a number of historical documents that suggest a long-standing connection between speakers of 'Kamilaroi' and the upper Hunter, 'as far south as Wollombi Brook'. There seems to be little disagreement that the 'Kamilaroi' occupied the headwaters of the Hunter and the area around Murrurundi, close to the watershed. Further down the Hunter Valley, the literature often depicts the Kamilaroi as intruders. In relation specifically to the 'Geawegal', Fison and Howitt say that the latter "were always in dread of war with the "Kamilaroi", who intruded down the heads of the Hunter across from Talbragar to the Munmurra waters, and even occasionally made raids as far as Jerry's Plains'. Wafer's paper attempts to throw some light on this matter, mainly through an analysis of placenames from the region, and then investigates some of the difficulties posed by landnám in the context of Aboriginal placenames. The term 'Geawegal' is investigated, since it has been given such prominence by Tindale and Horton and their scholarship remains the most influential record of Aboriginal language cartography.

Jim Smith's paper is concerned with the names of five caves in Gundungurra country which includes the catchments of the Wollondilly and Cox rivers. The caves are Jenolan, Womboyn, Tuglow, Colong, and Abercrombie. He analyses their etymology and their linguistic origins or etiology or 'the story behind the name'. He finds that Jenolan Caves and Colong Caves were named after nearby 
topographic features and are not the names of the localities to which they have been applied. He also discusses some of the meanings of the names in the sense of the mythological stories to which the names allude.

The next paper by Murray Garde concerns Western Arnhem Land in the Northern Territory. Garde notes that Australian Aboriginal cultures have dense systems of placenames, unsurprising given that they are used frequently in conversation and yet there has been little documentation of how placenames are used in interactions. In this paper he examines the pragmatics of placename use in everyday conversation in the Bininj Gunwok dialects of Western Arnhem Land. Gardes take an indexical approach to how placenames are used (and in certain contexts avoided) by the speaker in order to achieve a range of goals. These include recitation of placenames to create mental maps of walking routes, their use as deictics, personal expressions and their role in a certain kind of humorous language.

Fiona Powell's paper 'Locating Seven Rivers' is the first of two dealing with Queensland. Her paper describes the results of research about the Northern Cape York Peninsula (NCYP) placename 'Seven Rivers'. This placename occurs in the lexicons of English and NCYP Creole and in the NCYP ethno-historical, linguistic and genealogical records. It is also associated in these materials with places named 'Seven River', 'Severn River' and 'Seventh River'. Powell's initial research involved descendants of persons whose ancestors originated from places identified by these placenames. Powell established that there was no agreed view about whether these names referred to the same place or to different places, and her expanded investigation considers NCYP's wider toponymic history.

Jonathan Richards considers the naming of Mount Wheeler in central Queensland in the second contribution on Queensland. Many placenames in Queensland and Australia, at large, date from the frontier period. Some are ubiquitous but relatively harmless - for example, the many Rocky, Sandy and Stoney creeks - while other placenames are more sinister, including the various Murdering Creeks, Slaughterhouse Creeks, Skull Holes and Skeleton Creeks. These morbid names appear to refer to events that some Australians would rather forget, or deny ever happened. Richards further discusses a third group of names that commemorate pioneers, some of whom can also be connected with episodes of genocidal violence on the Australian frontier.

Nick Piper's paper is concerned with saltwater placenames around Mer in the Torres Strait. Specifically, the sources and meanings for saltwater placenames are examined based on the reefs and cays found around the Murray Islands (Mer, Dauar and Waier) in the eastern Torres Strait. These are named after ancestors, physical features such as shape, size, matter, location, wildlife or habitat, significant events. They can be conveyed literally or metaphorically. A singular 
feature of some saltwater placenames is their coincidence with a placename on land suggesting a close connection between land and sea. Comparisons with other Indigenous placename studies show remarkable similarities with a focus on the environment and its physical characteristics, connections to the flora and fauna, and mythological/ancestral associations. Furthermore, features from several categories are sometimes combined such as landscape and mythology. However, there are major differences with the mythological/ancestral names. While the Australian Aboriginal placenames evoke an event associated with the mythological being, the Meriam and Marquesan placenames are named overtly after the personal name of an ancestor.

South Australian toponymic issues are dealt with in the paper by Rob Amery and Vincent (Jack) Kanya Buckskin. They address some of the linguistic issues arising from the development of the Kaurna Placenames Database. They describe and analyse the linguistic issues arising in the course of developing a database of Kaurna placenames from the Adelaide Plains in South Australia. Kaurna people are in the process of reclaiming their identity and their language, a language that was considered to be 'extinct' by many or 'sleeping' by the people themselves. Kaurna people have expressed the view at Kaurna Warra Pintyandi (KWP) meetings that they wish to see Kaurna words spelt and pronounced correctly and they are keen to see that Aboriginal placenames in use on the Adelaide Plains conform to the sound patterns of the language. Consequently, names that appear to be of Indigenous origin are being sifted through - those that can be verified as Kaurna names are retained, others are discarded and some are translated into Kaurna or adapted into the Kaurna sound and spelling systems. The project is also attempting to pin down the meanings of Kaurna placenames. It can be shown that some etymologies previously recorded are fanciful, others verifiably false, while still others are highly questionable. In many cases we simply do not know. There are also difficulties in determining what a particular name relates to, or whether variants relate to the same word, or were in fact attempts to spell different though somewhat similar names. A set of principles for dealing with such uncertainty has been developed by KWP. Amery and Buckskin give many examples where these principles can be applied and other examples where they are still at a loss as to how we should deal with the names in question.

Luise Hercus's paper is entitled 'One name for one Place - but it is not always so'. She finds that Aboriginal placenames represent a very ancient layer of the vocabulary, just as placenames do in European traditions. Extensive work has been done on European river-names which, according to some scholars, are said to form the most ancient layer of the vocabulary, preceding the arrival of the Indo-Europeans. For a traditional Aboriginal person, as for the older Europeans, the geographical extent of their 'world' was much smaller than it is for people now in today's 'global village'. It was, however, infinitely more detailed and 
meaningful. Hercus looks at several aspects of Aboriginal placenames in the light of this: placenames may be old, but there is not an eternal relationship between a place and its name: there are cases of duplicates in name on the one hand, and dual naming on the other. Placenames are not immutable, there are cases where one can see new placenames evolve. Aboriginal placenames have special significance in the chronology of the creation of the landscape.

The final cluster of Australian papers is concerned with Victoria. Fred Cahir explores the question why did squatters in colonial Victoria use Indigenous placenames for their sheep stations? The archival records of many squatters in 19th century Victoria (formerly known as the Port Phillip District) often contain brief references to the processes involved in and decisions that led to the naming of their pastoral leases. This documentation in the official naming of a pastoral lease is unsurprising given that a squatter wishing to obtain a pastoral licence would have to register a legal document with the colonial government, stating the name of the run. What is perplexing is why a large number of pastoralists chose an Indigenous name. Most etymological discussions, in Australia at least, have largely centred on the placenames of towns, cities and geographical features such as rivers, mountains and lakes. The paper explores whether the same reasons Indigenous placenames were adopted in public spaces may also be applied to the private sphere of naming pastoral leases - the colonial desire to usurp placenames and their symbolism in 19th century frontier Australia.

Ian Clark discusses multiple Aboriginal placenames in western Victoria. In a recent paper on transparency versus opacity in Australian Aboriginal placenames, Michael Walsh noted that in 'Aboriginal Australia it is relatively common for a given place to have multiple names'. In providing an overview of multiple naming practices Walsh observed that he was unclear on how multiple naming operates and what its function is. Other than some case studies (such as, Schebeck on the Flinders Ranges, South Australia and Sutton on Cape York, Queensland) we are yet to gain a comprehensive picture of Aboriginal Australia. This paper builds on this discussion through a consideration of multiple naming in western Victoria using the results of research conducted by Clark and Heydon into Victorian Aboriginal placenames.

The second paper by Ian Clark is concerned with dissonance surrounding the Aboriginal origin of a selection of placenames in Victoria, Australia. In this paper Clark focuses on some 26 placenames for which there is dispute over their Aboriginal origin. These names are considered in some detail in an effort to resolve their lexical ambiguity to explain the reasons for the ambiguity and to find any patterns and causal factors. The merits of the claims and counter claims in each case are examined and an attempt made to categorise the assertion of Aboriginal etymology as either grounded in the historical evidence, or likely to be explained by folk etymology. The reasons for falsely attributing meanings 
include names based on structure or sound that may lack historical basis but have become accepted through common practice, or those names explained by false etymology that are unsupported by historical evidence or folk etymologies.

Laura Kostanski's paper is entitled 'Duel-Names: How toponyms can represent hegemonic histories and alternative narratives'. Place identity is stated to be a construct of emotional meaning through which societies assert social 'norms' and define cultural mores. Kostanski proposes that just as places assert hegemonic discourses, toponyms are powerful cultural tools utilised by societies to assist in defining social and cultural associations. Based on the available literature, place identity is formed through four key elements: history/memory, community, emotions and actions/events. Utilising data collected from residents near, or visitors familiar with, The Grampians (Gariwerd) National Park area in Victoria, Australia, (where the state government proposed in 1989-1990 to restore Indigenous names for the park and its various features) each of the four key elements is examined in an attempt to define whether they can form a new theory on toponymic identity. Kostanski asserts that those people who supported the restoration of Indigenous toponyms saw the potential for allocating countermemories to the mainstream (colonially dominated) local histories, whilst opponents perceived the proposal to be an interference with the connections they made to local history. The paper concludes that toponymic identity can be defined as a construct through which people form links to history, allocate their memories and assert cultural ideologies.

Edward Ryan's paper entitled 'Water for country, words for water; Indigenous placenames of north-west Victoria and south-west New South Wales' discusses placenames of Indigenous origin of north-west Victoria and south-west New South Wales, continuing an exploration begun in his article 'Blown to Witewitekalk' in the book The Land is a Map. The question of the existence of placenames for areas of country rather than just specific localities is considered while 'regional' names and more specific placenames are examined in the light of their origin as sites of significance in creation stories, reflections of natural features or local flora. All featured placenames are considered in the light of the Aboriginal sources where identifiable and the relationships specific informants had to particular places across the region.

Moving on to Norfolk Island, Joshua Nash's paper is entitled 'Obtuse anglers: The linguistics and ethnography of fishing ground names on Norfolk Island'. The paper finds that fishing ground names provide an excellent example of place-creation being brought into existence by human necessity to name and remember. They are utilitarian placenames that are rarely mapped; they are easily forgotten and are some of the most ephemeral aspects of a people's toponymic inventory: 
It is not much use taking bearings if they are not accurately recorded for future reference. The human memory for such details is fickle and the eye is easily deceived. ... It is asking a lot to try to carry details of four points in the mind for each fishing point that may be worked. It is imperative that they be recorded, and it is a good idea to mark them on an Admiralty chart in similar manner [sic] to that used in our sketch. (Hardy 1974:227)

Nash's paper considers the historical and theoretical background of the toponymic role of fishing ground names. The relevance of fishing ground names to Norfolk toponymy and the Norf'k language is also outlined. A tagmemic analysis of Norf'k fishing ground forms offers reasons for the formal structure of these names. Finally a detailed analysis of a single fishing ground name is used to explore the role Norf'k fishing ground names hold in Norfolk toponymy as a whole and how fishing ground names can contribute at least in part to the writing of Norfolk's 'toponymic ethnography'.

The final cluster of papers is concerned with international perspectives into aspects of indigenous and minority placenames. In the first paper Kaisa Rautio Helander, considers power relations and representation in Sámi placenames. Language plays an important role in forming the social world and it is used to construct and shape social and political reality. According to Clark and Dear, 'language is studded with signs, icons or symbols, which may carry meanings in excess of the simple word being used'. Power relations are also institutionalised in language, at the same time as it functions as a means of social contact and communication. Language has the effect of including or excluding various groups and individuals according to their perception of the linguistically created 'reality'. As Taylor points out, 'it is language which enables us to draw boundaries, to pick some things out in contrast to others. Thus through language we formulate things, and thus come to have an articulated view of the world'.

The next paper from Huia Pacey is entitled 'Please adjust your bearings...' As an integral component of Māori culture, placenames are critical to maintaining identity and relationship to place. This paper will explore how 19th century survey programmes continue to affect contemporary identity relationships with place. It offers examples but looks beyond the historical narrative of a landscape where indigenous placenames were overlaid by early European explorers and colonists names - some of which are being re-commemorated by dual place naming. The purpose of the paper however, is to discuss a new placenaming phenomenon in New Zealand - where some land title appellations are changing to those of an imported survey system. This will mean some parcels of land will have three different names - the traditional, the historic and now the 'legal'. It is ironic when framed against the increase of dual placenames in New Zealand that names of land blocks attached to placenames commemorating ancestral 
connection may now be consigned to the 'other' alternative name. For a culture that relies on placenames as an integral part of identity - how will Māori preserve that relationship through future generations when their land blocks are named after and represented by a surveyors grid block?

Lynn Peplinski's paper concerns the Inuit languages in Canada. Canada is officially a bilingual nation with both English and French enjoying equal status even though only 23 per cent of the population considers French as their mother tongue and an overwhelming majority of Francophones (18.5 per cent) are concentrated in one province, the province of Quebec. Nunavut is a large territory of nearly 2 million $\mathrm{km}^{2}$ comprising about one fifth of Canada's land mass. This large area has been home to Inuit and their predecessors for the past 4000 years. Today Nunavut boasts a population of about 27,000, 85 per cent of whom are Inuit, scattered in 23 communities. There are arguably two Inuit languages in Nunavut. Inuktitut is spoken in all but two communities, where Inuinnaqtun is spoken. Each community is made up of speakers of one or more language dialects depending upon where the family groups' ancestors lived prior to moving into established communities around 50 years ago. There can be many dialects present in one community, again depending on the land where individual families resided prior to moving into established settlements. Inuit Heritage Trust policy regarding naming features on maps aims to capture the most appropriate dialect for the place where possible. Thus, the dialects of descendants of family groups still closely tied to certain geographical areas will receive priority. Names for the same features in other dialects would appear in the legend of the map. This effort is also explicitly noted on the individual map sheets - an example of which Peplinski reproduces in this publication. The Inuit Heritage Trust has developed a theoretical model to address overlapping names for features between communities but it is as yet untested.

Moving to South Africa, Peter Raper considers Khoisan indigenous toponymic identity. The term Khoisan refers to the Khoikhoi ('Hottentot') and San ('Bushman'), and to the languages spoken by them. These people are the indigenous peoples of Southern Africa, and were the first to name features of the landscape. African peoples migrated southwards from Central Africa, followed by French, Dutch, British, German and other peoples from Europe and Asia. Each wave of migrants adopted existing placenames, adapting them phonologically and later orthographically, translating some names fully or partially, and bestowing new names in their own language. On the basis of lexical meanings of the names preserved in oral tradition or written records, and by syntactic and morphological analysis, African and European language names are shown in many cases to be adaptations, translations and folk-etymological interpretations of original Khoisan names. To demonstrate this, phonological processes and semantic comparisons are employed, and syntactic constructions 
of African language names compared with those of Khoisan ones. Lexical cognates are indicated and sound-shifts identified, many displaying click replacements, coalescence of vowel clusters, consonant and vowel adaptation, etc.

The focus of the Ballarat conference was current trends in toponymic research as they relate to Indigenous and minority placenames. The papers presented here provide us with insight into the quality of the research that is being undertaken here in Australia and in other countries such as Canada, Finland, South Africa, New Zealand, and Norway.

\section{Reference}

Hardy, W. 1974, The Saltwater Angler, Fifth edition, Murray, Sydney. 
This text taken from Indigenous and Minority Placenames: Australian and International Perspectives, Edited by Ian D. Clark, Luise Hercus and Laura Kostanski, published 2014 by ANU Press, The Australian National University, Canberra, Australia. 